Schweizerisches Jahrbuch für Entwicklungspolitik

16 | 1997

Umwelt und Entwicklung, Rio : Fünf Jahre danach

\title{
Darstellung der Dossier
}

\section{(2) OpenEdition}

1 Journals

Electronic version

URL: http://journals.openedition.org/sjep/745

DOI: $10.4000 /$ sjep.745

ISSN: 1663-9677

Publisher

Institut de hautes études internationales et du développement

Printed version

Date of publication: 1 mars 1997

Number of pages: 187-188

ISSN: 1660-5926

\section{Electronic reference}

" Darstellung der Dossier », Schweizerisches Jahrbuch für Entwicklungspolitik [Online], 16 | 1997, Online erschienen am: 13 August 2012, abgerufen am 08 September 2020. URL : http:// journals.openedition.org/sjep/745; DOI : https://doi.org/10.4000/sjep.745

(c) The Graduate Institute 


\section{DOSSIER}

\section{UMWELT UND ENTWICKLUNG RIO: FÜNF JAHRE DANACH}

nter den Themenbereichen, die auf den Konferenzen der Uruguay-Runde nicht erfolgreich abgeschlossen werden konnten, sind zwei Themen von grosser Bedeutung für die Entwicklungsländer, die sie gleichzeitig mit Besorgnis erfüllen:

$\square$ die Beziehungen zwischen dem Welthandel und den Arbeitsbedingungen in den Exportländern, die sogenannte Frage der "Sozialklauseln";

$\checkmark$ die Rolle der Umweltbeziehungen in den internationalen Wirtschaftsbeziehungen, die Frage des "Rio-Folgeprozesses".

Mit dem ersteren Thema haben wir uns im Jahrbuch Schweiz Dritte Welt 1996 im Dossier "Sozialklauseln und Nord-Süd-Handel" befasst. In diesem Jahr behandeln wir die Rolle der Umweltproblematik in den verschiedenen Dimensionen der Beziehungen zwischen Industrie- und Entwicklungsländern, wobei wir besonderes Gewicht auf die Politik der Schweiz im Umweltbereich legen.

Es wird heute anerkannt, dass es im gemeinsamen Interesse aller Nationen liegt, ein sogenanntes "nachhaltiges" Entwicklungsmodell zu konzipieren und umzusetzen, das weltweit eine gerechtere Wohlstandsverteilung und gleichzeitig die langfristige Erhaltung der menschlichen Gesellschaft gewährleistet.

Der Übergang zu diesem Modell gestaltet sich für die verschiedenen Kategorien von Ländern sehr unterschiedlich; es liegt auf der Hand, dass die Schweiz und Burkina Faso in dieser Beziehung nicht die gleichen Prioritäten haben können. Für die Entwicklungsländer geht es darum, darauf zu achten, dass das Wirtschaftswachstum, welches erforderlich ist, um der gesamten Bevölkerung einen angemessenen Lebensstandard zu sichern, nicht dazu beiträgt, den Druck der menschlichen Aktivitäten auf die natürlichen Ressourcen zu verstärken. Für die Industrieländer geht es darum, ein Entwicklungsmodell zu finden, das es gestattet, den Pro-Kopf-Verbrauch bestimmter Ressourcen - zum Beispiel fossiler Energien - zu senken und gleichzeitig die Lebensqualität für die gesamte Bevölkerung zu erhalten bzw. zu verbessern. Die Harmonisierung dieser doppelten Vorgehensweise zur Erreichung einer "nachhaltigen" Entwicklung geht nicht ohne Interessenkonflikte, Missverständnisse und Misstrauen in den Nord-SüdBeziehungen vor sich.

Unser Dossier beginnt mit einem Beitrag von Franco Romerio und Milad Zarin-Nejadan, der den Stand der Wechselbeziehungen zwischen Umwelt und 
Entwicklung ermittelt und die verschiedenen finanziellen, kommerziellen Instrumente sowie die Instrumente der Entwicklungszusammenarbeit aufführt, mit denen die Umweltdimension in die Nord-Süd-Beziehungen eingebunden werden kann.

Danach werden drei spezifischere Themen behandelt:

a) Die Beziehung zwischen Welthandel und Umwelt, mit

a einem Artikel von Sophie Forster, der den Stand der internationalen Verhandlungen (in WTO, UNCTAD und OECD) im Bereich Handel und Umwelt vorstellt;

口 einem Beitrag von René Vossenaar über die Auswirkungen der Umweltkennzeichnung auf die Umwelt und den Handel der Entwicklungsländer;

- einer Darlegung der Problematik der mit den sozialen und ökologischen Produktionsbedingungen im Textil- und Bekleidungssektor verbundenen Labels durch Dorothea Rüesch; die Beispiele sind der Situation auf dem Schweizer Markt entnommen.

b) Der Technologietransfer im Bereich des Umweltschutzes. Nachdem Andràs November das "Umwelttechnologie"-Konzept vorgestellt hat, untersucht er die Rolle und die Instrumente der Zusammenarbeit mit den Entwicklungsländern zur Förderung des Transfers umweltfreundlicher Technologien.

c) Schliesslich wird im Artikel von Michèle Rajaonarivony analysiert, in welchem Ausmass und mit welchen Ergebnissen die Umweltdimension in das bedeutende Programm der bilateralen Zusammenarbeit zwischen der Schweiz und Madagaskar integriert wurde.

Ferner umfasst der Teil "Analysen und Stellungnahmen" einen Artikel von Catherine Schümperli Younossian über den illegalen Handel mit Kulturgütern - eine seit langem bestehende, aber unbekannte Dimension der Nord-Süd-Beziehungen. In diesem Beitrag wird die Rechtslage in der Schweiz zu einem Zeitpunkt untersucht, zu dem der Bundesrat sich anschickt, den eidgenössischen Räten die Ratifikation wichtiger internationaler Konventionen zur Bekämpfung des illegalen Handels mit Kunstgütern vorzuschlagen. 